\title{
TRANSMYOCARDIAL LASER REVASCULARIZATION FAILS TO PREVENT LEFT VENTRICULAR FUNCTIONAL DETERIORATION AND ANEURYSM FORMATION AFTER ACUTE MYOCARDIAL INFARCTION IN SHEEP
}

Ramin Malekan, MD $^{\mathrm{a}}$

Scott T. Kelley, MDa

Yasuyuki Suzuki, MD ${ }^{\mathrm{a}}$

Carol Reynolds, $\mathrm{MD}^{\mathrm{b}}$

Theodore Plappert, CVT ${ }^{\mathrm{a}}$

Martin St.-John Sutton, MD ${ }^{a}$

L. Henry Edmunds, Jr, MD ${ }^{\mathrm{a}}$

Charles R. Bridges, MD, ScD ${ }^{\mathrm{a}}$
Objective: Transmyocardial laser revascularization is an investigational technique for revascularizing ischemic myocardium in patients with inoperable coronary arterial disease. This study tests the hypothesis that laser revascularization prevents left ventricular functional deterioration and aneurysm formation after acute anteroapical myocardial infarction. Methods: An ultrasonic ascending aortic flow probe and snares around the distal left anterior descending and second diagonal coronary arteries were placed in 26 Dorsett hybrid sheep. Ten to 14 days later, snared arteries were occluded to produce an anteroapical infarction of $23 \%$ of left ventricular mass. Before infarction 14 animals had $34 \pm 4$ transmyocardial perforations in the area of the anticipated infarction made with a carbon dioxide laser. Twelve animals served as controls. Hemodynamic measurements and transdiaphragmatic quantitative echocardiograms were obtained before, immediately after, and 2, 5, and 8 weeks after infarction. Eighteen sheep completed the protocol. Results: All animals had large anteroapical left ventricular aneurysms with massive ventricular enlargement. Immediately after infarction the anterior wall became thinner and dyskinetic in all sheep. At 8 weeks aneurysmal size and shape were indistinguishable between groups. Two days after infarction, laser holes were filled with fibrin. At 5 and 8 weeks the infarct consisted of dense collagen, fibroblasts, scattered calcifications, myocyte fragments, neutrophils, macrophages, and no laser holes. There were no significant differences at any time between groups for cardiac pressures or output, ventricular volumes, ejection fraction, stroke work, and the stroke work-left ventricular end-diastolic pressure index. Conclusion: Transmyocardial laser perforations do not revascularize acute myocardial infarction in sheep. ( $J$ Thorac Cardiovasc Surg 1998;116:752-62)
$E^{p}$ picardial and endocardial laser revascularization is investigative therapy for symptomatic patients with inoperable coronary arterial disease. The method is

From the Department of Surgery a and Department of Pathology and Laboratory Medicine, ${ }^{\mathrm{b}}$ University of Pennsylvania, Philadelphia, $\mathrm{Pa}$

Supported by grant HL36308 from the National Heart, Lung and Blood Institute, National Institutes of Health, Bethesda, Md.

Read at the Seventy-eighth Annual Meeting of The American Association for Thoracic Surgery, Boston, Mass, May 3-6, 1998.

Received for publication April 6, 1998; revisions requested June 10, 1998; revisions received June 26, 1998; accepted for publication July 1, 1998 .

Address for reprints: Charles R. Bridges, MD, ScD, Department of Surgery, 4 Silverstein, Hospital of the University of Pennsylvania, Philadelphia, PA 19104-4283.

Copyright $(0) 1998$ by Mosby, Inc.

$0022-5223 / 98 \$ 5.00+0 \quad \mathbf{1 2 / 6 / 9 2 8 0 9}$ intuitively attractive and has precedent in reptilian anatomy. ${ }^{1}$ Investigational studies over the past decade consistently demonstrate that laser treatment of ischemic myocardium relieves angina, reduces intake of antianginal medications, and modestly increases exercise tolerance. ${ }^{2,3}$ However, imaging and postmortem histologic studies fail to demonstrate enduring patency of transmural or partial thickness channels ${ }^{4-7}$; thus the mechanism of anginal relief remains unclear. Demonstrations of efficacy by in vivo radionuclide studies and positron emission tomograms are inconclusive. ${ }^{2,3}$ Histologic evidence is consistent with a nonspecific inflammatory response to injury. ${ }^{4,5,8}$

Laser revascularizations are designed to increase blood flow to areas of ischemic, but viable myocytes (ie, hibernating myocardium). Hibernating myocardium is difficult to model in animals ${ }^{5}$ and not easily nor reli- 
ably detected in patients ${ }^{9}$; therefore most investigators use coronary arterial occlusion or ischemia/reperfusion animal models. In dogs and pigs, preformed collateral coronary vessels ${ }^{10,11}$ attenuate ischemia and thus confound interpretations of laser treatment. ${ }^{12}$

This study tests the hypothesis that laser revascularization at the time of acute anteroapical myocardial infarction preserves cardiac myocytes and prevents infarct expansion in a sheep model. This model was chosen for several reasons. Sheep do not have preformed collateral coronary vessels. ${ }^{13}$ Anteroapical infarctions consistently evolve into large, discrete anteroapical aneurysms over 8 weeks. ${ }^{14}$ Serial functional studies and images of ventricular morphologic condition provide sensitive and relevant measures of the efficacy of laser therapy. ${ }^{15}$

\section{Methods}

Surgical protocol. Anesthesia was induced with thiopental sodium (10 to $15 \mathrm{mg} / \mathrm{kg}$ ) in 26 Q-fever negative, Dorsett hybrid sheep, and the animals were intubated, anesthetized with isoflurane (1.5\% to $2 \%$ ) in oxygen, and mechanically ventilated (Drager and anesthesia monitor; North American Drager, Telford, $\mathrm{Pa})$. All animals received glycopyrolate $(0.4$ $\mathrm{mg}$, intravenously) and cefazolin ( $1 \mathrm{~g}$, intravenously) before anesthesia. The surface electrocardiogram and brachial or femoral arterial blood pressure were continuously monitored. Animals were treated in compliance with $\mathrm{NIH}$ publication No. 85-23 as revised in 1985.

All animals had sterile left anterolateral thoracotomy in the fifth intercostal space. Polypropylene snares were placed around the homonymous and second diagonal coronary arteries approximately $40 \%$ from the apex. (The homonymous artery is equivalent to the human left anterior descending coronary artery [LAD].) The anticipated infarct area of approximately $23 \%$ of left ventricular (LV) mass $^{14}$ was marked with an epicardial 2-0 silk suture. An ultrasonic flow probe (Transonic Systems, Inc, Ithaca, NY) was placed around the aortic root proximal to the origin of the brachiocephalic artery. Two epicardial pacemaker wires were sewn to the left atrium. The chest was closed, and the pacing wires and flow probe connection were exteriorized. Sheep received cefazolin ( 1 g every 8 hours, intravenously) for 3 days.

Baseline data. Seven to 10 days after instrumentation, animals were anesthetized, intubated, and mechanically ventilated as before. Sheep were placed supine, and surface electrocardiogram and arterial blood pressure were continuously monitored. A Swan-Ganz thermodilution catheter (131 h-7F; Baxter Healthcare Corp, Irvine, Calif) was introduced via the left external jugular vein for measurement of pulmonary artery and pulmonary artery occlusion pressures. A highfidelity pressure transducer (Spc-350; Millar Instruments, Inc, Houston, Tex) was inserted via the femoral or carotid artery into the LV for continuous LV pressure monitoring.

Animals were atrially paced at 120 beats/min and were disconnected from the ventilator for all hemodynamic measurements.
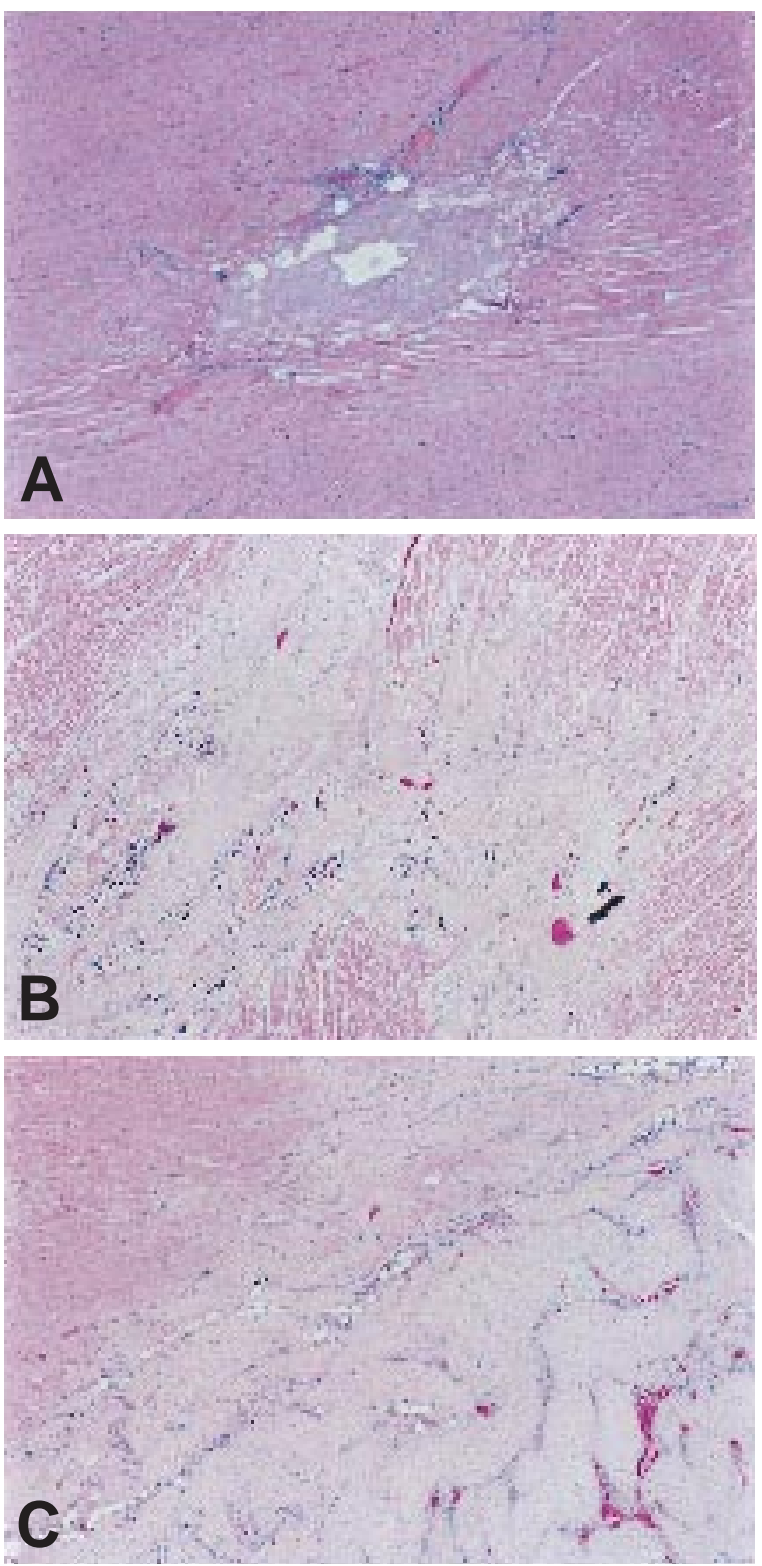

Fig 1. A, Microscopic section of myocardium 48 hours after infarction in a sheep that died of an arrhythmia. This animal had transmyocardial laser perforations immediately before infarction. The area of laser channel is clearly seen. The channel is occluded by fibrin. (Hematoxylin and eosin, original magnification $\times 50$.) B, Laser-treated myocardium 5 weeks after infarction. The infarction (at its edge) is nearly completely replaced by fibrous tissue and scattered calcifications. Cardiac myofibroblasts predominate; a few cardiac myocyte remnants, neutrophils and macrophages are present in the infarct. (Hematoxylin and eosin, original magnification $\times 25$.) $\mathbf{C}$, Lasertreated myocardium 8 weeks after infarction. This section was taken from the edge of the infarct. The infarct has healed as a fibrous scar nourished by small blood vessels. Cardiac myocytes and inflammatory cells are absent. No laser channels are seen. (Hematoxylin and eosin, original magnification $\times 25$.) 

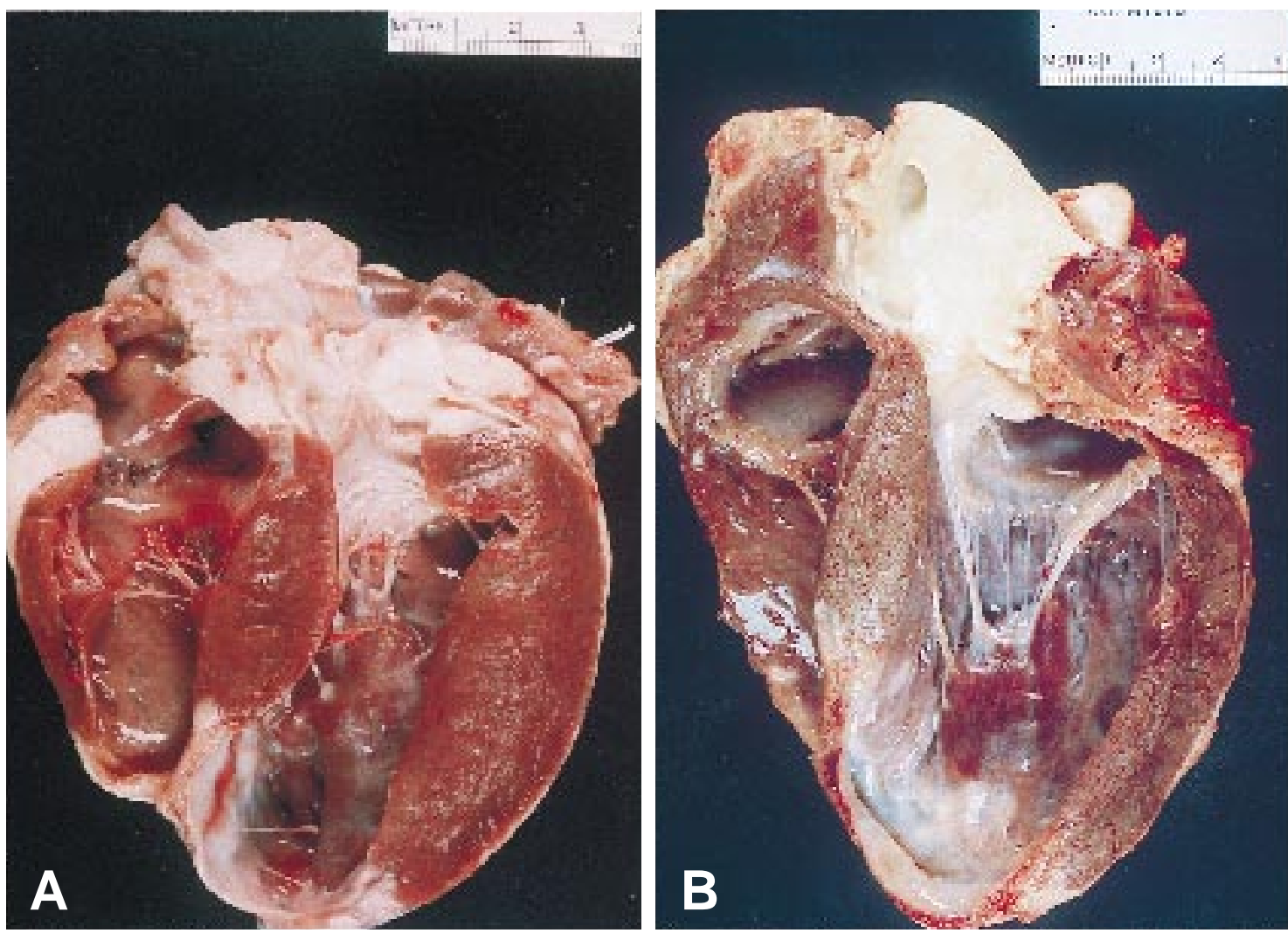

Fig 2. Long-axis views of a control heart (A) and a heart treated by transmyocardial laser perforations (B) 8 weeks after infarction. Both hearts are enlarged, and borders of the aneurysym are sharp and distinct. The aneurysm involves the anteroapical wall, part of the septum, and a small apical portion of the right ventricle.

Echocardiography. Subdiaphragmatic 2-dimensional echocardiographic images were obtained through a sterile midline or subcostal laparotomy incision ${ }^{15}$ using a $5 \mathrm{MHz}$ probe (77020A; Hewlett-Packard, Palo Alto, Calif) and were recorded on videotape. Short-axis images at 3 levels of the LV (approximating infarct, border zone, and remote myocardium) and 2 orthogonal long-axis views were obtained. Long-axis views were recorded during apnea and were used to calculate end-diastolic and end-systolic cavity volumes by biplane Simpson's rule. ${ }^{16}$

Diastolic and systolic wall thickness of the anterior LV wall in the area of infarction was measured before and 1 hour and 8 weeks after infarction in all sheep. Total and cavity areas of short-axis views also were measured in the area of infarction at the same time points. The perimeter length of the akinetic/dyskinetic wall segment was determined 8 weeks after infarction in all sheep.

Stroke work. Stroke work (SW) was calculated from simultaneous measurements of aortic flow and LV pressure ${ }^{17}$ :

Equation 1

$\mathrm{SW}(\mathrm{ergs})=\int_{\text {beat }} \mathrm{LVP}(\mathrm{mm} \mathrm{Hg}) \times \mathrm{Q}(\mathrm{mL} / \mathrm{sec}) \times \mathrm{dt}(\mathrm{sec}) \times 1330$,

where $L V P$ is $\mathrm{LV}$ pressure, $Q$ is aortic flow, and $d t$ is the time differential in seconds. Stroke volume (SV) is equal to the average SV over 10 beats, where SV is calculated as in equation 2 .

Equation 2

$$
\mathrm{SV}(\mathrm{mL})=\int_{\text {beat }} \mathrm{Q}(\mathrm{mL} / \mathrm{sec}) \times \mathrm{dt}(\mathrm{sec})
$$

Measurements were repeated 5 times with 3-minute intervals between data runs. Means of 5 data sets were used for the subsequent analysis.

Slope of the SW-LV end-diastolic pressure relationship. Global LV function was also estimated by relating SW to LV end-diastolic pressure (LVEDP). A $50 \mathrm{~mL}$ Fogarty catheter (US Catheter and Instrument Co, Glen Falls, NY) was placed into the vena cava via the right external jugular vein with fluoroscopic guidance and was inflated to decrease ventricular preload. SW was measured over the subsequent 10 beats and plotted against LVEDP. The slope of the relationship and correlation coefficient was calculated. In all cases, the correlation coefficient was greater than 0.92 , and typically the correlation coefficient was approximately 0.99. Caval occlusions were repeated 5 times, and the mean slope of all the 5 measurements was recorded.

Laser revascularization and myocardial infarction. After baseline measurements were taken, animals were randomly assigned to 2 groups: control (group I, $\mathrm{n}=12$ ) and the 

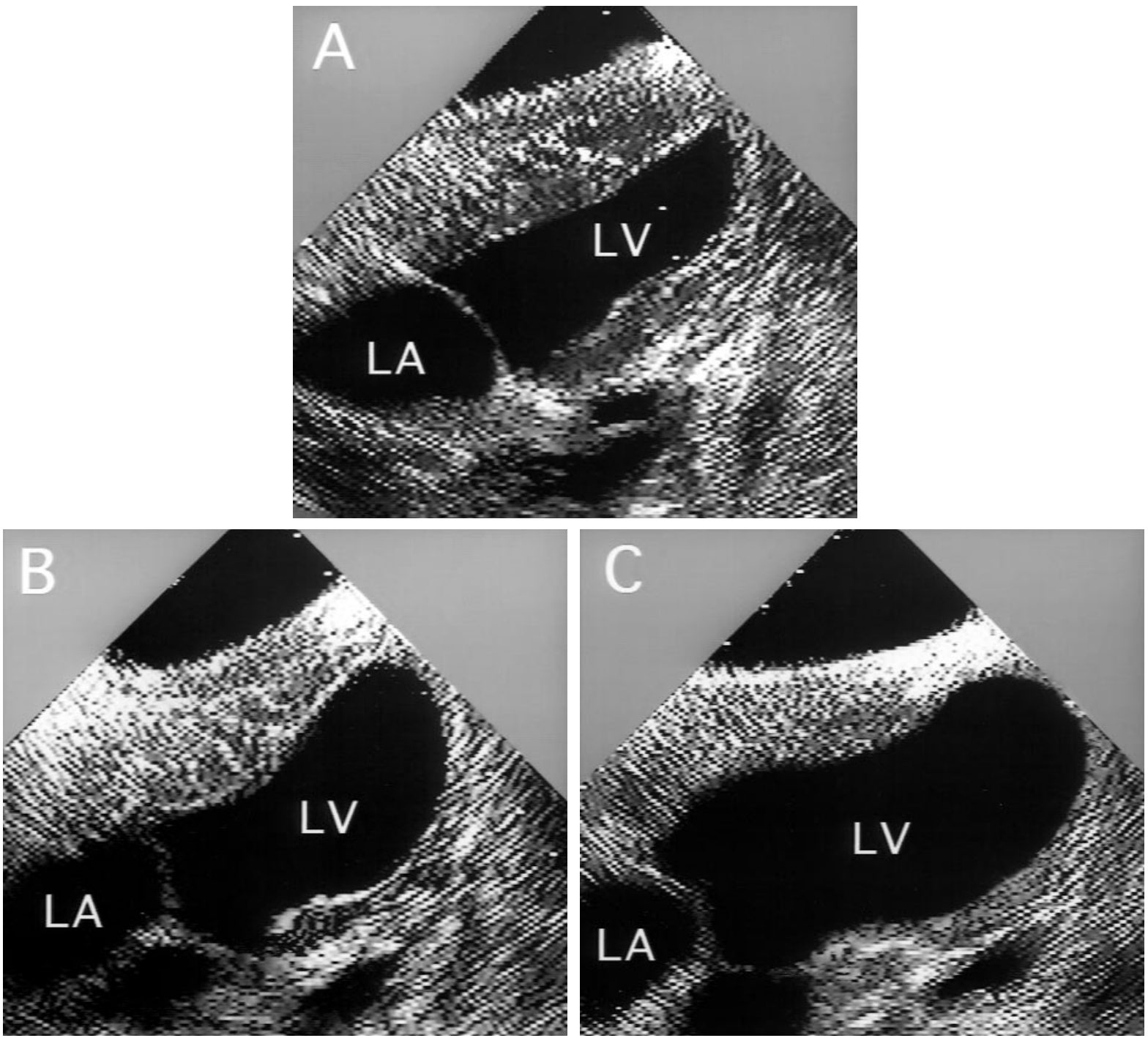

Fig 3. Echocardiographic long-axis views of the LV of a control animal immediately before infarction (A), 1 hour after infarction (B), and at 8 weeks (C). Immediately after infarction, the LV enlarges and the anterior wall becomes thinner and dyskinetic. Compare these echocardiograms with Fig 4. LA, Left atrium.

laser group (group II, $\mathrm{n}=14$ ). In the laser group before infarction, animals were placed in the right lateral decubitus position and underwent a repeat thoracotomy through the previous incision. A total of $34 \pm 4$ (SD; range, 29-42) transmural channels (approximately 4 channels per square centimeter) were created within 15 to 20 minutes in the area of the anticipated infarct, which was marked by suture with an 800-W carbon dioxide laser and 25 to $30 \mathrm{~J}$ (The Heart Laser; PLC Medical Systems, Telford, Mass). Creation of all laser channels was confirmed by appearance of pulsating bright red blood from the left ventricle. Bleeding from channels was controlled by either digital pressure or a superficially placed nonabsorbable 4-0 suture.

In both groups, exteriorized snares were pulled up to produce infarction immediately after completion of laser revas- cularization $(8.9 \pm 4.6$ minutes $)$. Control animals had similar infarctions but did not undergo a second thoracotomy. Arterial blood gases and plasma electrolytes were monitored before and during infarction, and abnormalities were corrected. Animals received a lidocaine bolus ( $\mathrm{mg} / \mathrm{kg}$, intravenously) and continuous infusion at $2 \mathrm{mg} / \mathrm{min}$. Arrhythmias were controlled with lidocaine, bretylium, esmolol, and magnesium. After the circulation stabilized, the chest was closed in layers.

Approximately 1 hour after infarction, hemodynamic and echocardiographic measurements were repeated in both groups. The laparotomy incision was closed, and animals were allowed to recover.

Follow-up studies. The sheep were followed up, and identical measurements were made at 2, 5, and 8 weeks after infarction. The laparotomy incision was moved between the left and 


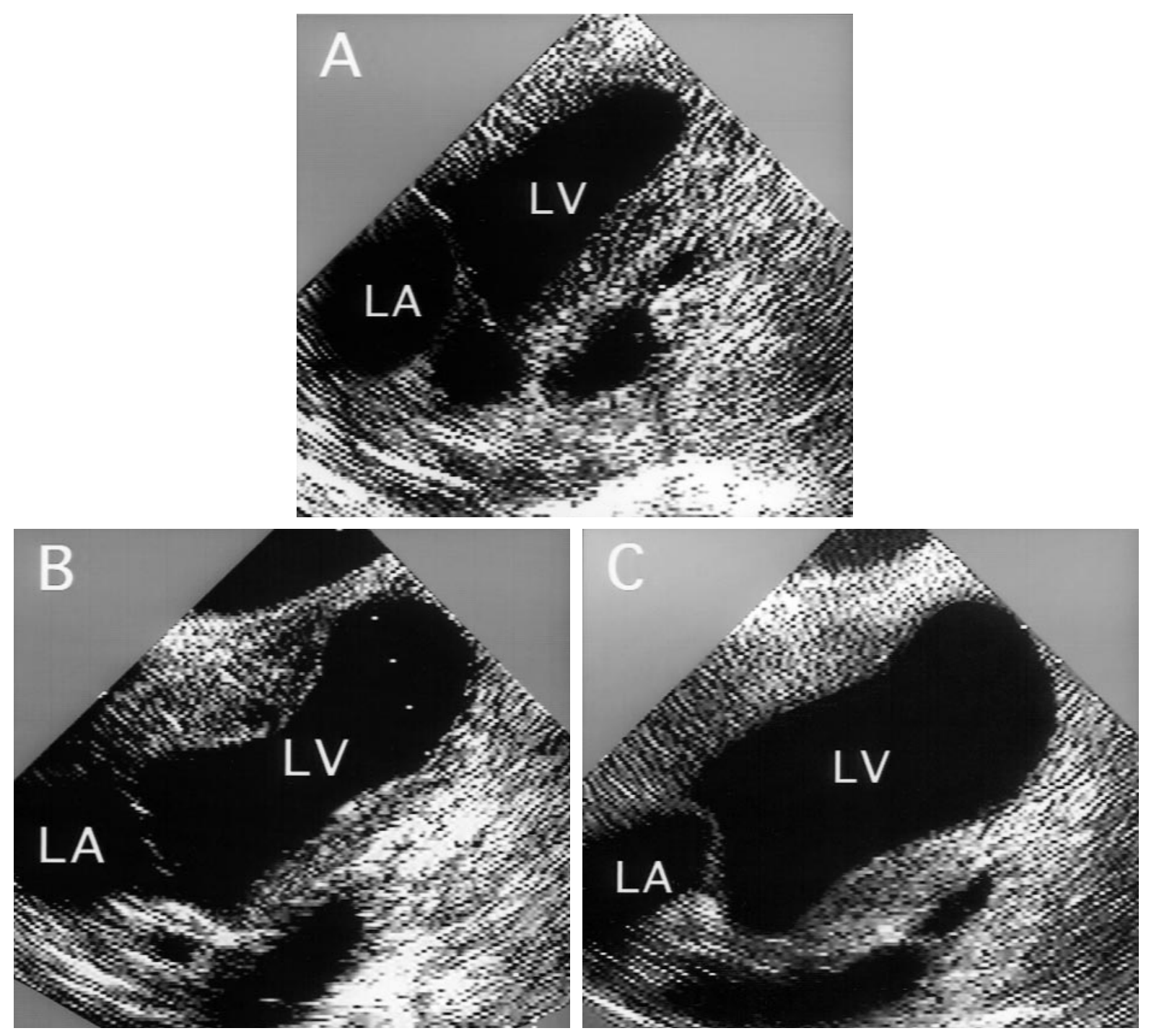

Fig 4. Long-axis echocardiographic views of the LV of a laser-treated animal immediately before both laser perforations and infarction (A), 1 hour after infarction $(\mathbf{B})$, and at 8 weeks $(\mathbf{C})$. Compare these echocardiograms with Fig 3. $L A$, Left atrium.

right subcostal incisions and the midline to reduce wound complications. After the 8-week study, animals were killed with a bolus of pentothal $(10 \mathrm{mg} / \mathrm{kg}$, intravenously) and potassium chloride $(80 \mathrm{mEq})$. The heart was excised, opened in the long axis, photographed, and fixed in $10 \%$ neutral buffered formalin. Infarcted myocardium was sliced at 1.5 - to 2-mm intervals perpendicular to the long axis of laser channels from epicardium to endocardium. Sections were embedded in paraffin, cut at $5 \mu \mathrm{m}$ intervals, and stained with hematoxylin and eosin. Trichrome stains were performed to highlight areas of fibrosis. All sections were examined microscopically.

Statistics. Measurements are reported as means and standard deviations. Differences between the 2 groups are compared by 2-way ANOVA (group, time), with Bonferroni adjustment for repeated measures (Statistical Package for the Social Science Program 6.0: SPSS, Inc, Chicago, Ill). If the time effect was significant $(P<.05)$ differences between preinfarction and subsequent measurements were compared by the paired $t$ statistic. When the group effect was significant, differences between groups at specific times were compared by the unpaired $t$ statistic.

\section{Results}

Twenty-six animals (12 control, 14 laser) underwent instrumentation and infarction. Eighteen sheep (10 control, 8 laser) completed the 8 -week protocol. Two animals in the control group and 4 animals in the laser group died after infarction and before the 2-week study secondary to postinfarction arrhythmias. Two animals in the laser group died after the 5-week study; one 
Table I. Selected echocardiographic measurements

\begin{tabular}{|c|c|c|c|c|c|c|}
\hline & \multicolumn{3}{|c|}{ Group I } & \multicolumn{3}{|c|}{ Group II } \\
\hline & Baseline & One hour & Eight weeks & Baseline & One hour & Eight weeks \\
\hline Diastolic WT (mm) & $9.0 \pm 1.1$ & $8.7 \pm 1.2$ & $4.8 \pm 0.3$ & $8.0 \pm 1.2$ & $7.8 \pm 1.2$ & $4.5 \pm 0.6$ \\
\hline Systolic WT (mm) & $11.3 \pm 1.2$ & $9.1 \pm 3.2$ & & $10.6 \pm 1.3$ & $7.9 \pm 1.3$ & \\
\hline Change from baseline, WT, diastole (\%) & & -3.3 & -46.7 & & -2.5 & -43.8 \\
\hline Change from baseline, WT, systole (\%) & & -19.5 & & & -25.5 & \\
\hline Diastolic CA $\left(\mathrm{cm}^{2}\right)$ & $7.2 \pm 2.1$ & $6.8 \pm 1.7$ & $10.2 \pm 2.6$ & $5.7 \pm 1.9$ & $4.5 \pm 1.8^{*}$ & $9.9 \pm 2.7$ \\
\hline Systolic CA $\left(\mathrm{cm}^{2}\right)$ & $4.2 \pm 1.8$ & $8.1 \pm 2.3$ & $11.6 \pm 3.3$ & $3.6 \pm 2.4$ & $6.0 \pm 2.0$ & $12.9 \pm 4.1$ \\
\hline Change from baseline, $\mathrm{CA}$, diastole $(\%)$ & & -5.6 & +41.7 & & -21.1 & +73.7 \\
\hline Change from baseline, CA, systole (\%) & & +92.9 & +176.2 & & +66.7 & +258.3 \\
\hline Long axis perimeter, diastole $(\mathrm{cm})$ & & & $18.9 \pm 1.4$ & & & $19.0 \pm 1.4$ \\
\hline Long axis perimeter, systole $(\mathrm{cm})$ & & & $18.4 \pm 1.3$ & & & $18.1 \pm 1.2$ \\
\hline Length akinetic/dyskinetic segment $(\mathrm{cm})$ & & & $8.0 \pm 1.4$ & & & $8.2 \pm 1.4$ \\
\hline
\end{tabular}

$W T$, Wall thickness; $C A$, cavity area. Values are from images that contain the infarcted or anticipated infarcted segment. Wall thickness measurements describe the infarcted segment before and after infarction. At 8 weeks, there was no change in infarct wall thickness during the cardiac cycle. Values are mean \pm SD.

${ }^{*} P=.01$, between groups; obtained by unpaired $t$ statistic.

Table II. Hemodynamic measurements

\begin{tabular}{|c|c|c|c|c|c|c|c|c|c|}
\hline \multirow[b]{2}{*}{ Measurement } & \multirow[b]{2}{*}{ Group } & \multirow{2}{*}{$\begin{array}{l}\text { Before } \\
\text { infarct }\end{array}$} & \multirow{2}{*}{$\begin{array}{c}\text { After } \\
\text { infarct }^{*}\end{array}$} & \multirow{2}{*}{$\begin{array}{c}\text { Two } \\
\text { weeks* }\end{array}$} & \multirow{2}{*}{$\begin{array}{l}\text { Five } \\
\text { weeks }\end{array}$} & \multirow{2}{*}{$\begin{array}{c}\text { Eight } \\
\text { weeks* }\end{array}$} & \multicolumn{3}{|c|}{ Two-way ANOVA (P value) } \\
\hline & & & & & & & Time & Group & Interaction \\
\hline \multirow[t]{2}{*}{ Number } & Control (I) & 12 & 12 & 10 & 10 & 10 & & & \\
\hline & Laser (II) & 14 & 14 & 10 & 10 & 8 & & & \\
\hline \multirow{2}{*}{$\begin{array}{l}\text { Arterial pressure } \\
(\mathrm{mm} \mathrm{Hg})\end{array}$} & Control (I) & $74 \pm 7$ & $63 \pm 6(.00)$ & $69 \pm 6$ & $69 \pm 4$ & $71 \pm 15$ & \multirow[t]{2}{*}{0} & \multirow[t]{2}{*}{.14} & \multirow[t]{2}{*}{.35} \\
\hline & Laser (II) & $77 \pm 7$ & $64 \pm 8(.00)$ & $72 \pm 7$ & $76.6 \pm 11$ & $69 \pm 12$ & & & \\
\hline \multirow[t]{2}{*}{ LVESP (mm Hg) } & Control (I) & $88 \pm 9$ & $81 \pm 9$ & $81 \pm 9$ & $79 \pm 7$ & $79 \pm 7$ & \multirow[t]{2}{*}{.02} & \multirow[t]{2}{*}{.86} & \multirow[t]{2}{*}{.35} \\
\hline & Laser (II) & $86 \pm 7$ & $78 \pm 11$ & $80 \pm 10$ & $86 \pm 12$ & $77 \pm 12$ & & & \\
\hline \multirow[t]{2}{*}{ LVEDP (mm Hg) } & Control (I) & $1.8 \pm 1.0$ & $7.9 \pm 3.5(.00)$ & $6.4 \pm 5.4(.02)$ & $5.8 \pm 1.9$ & $6.1 \pm 3.0(.03)$ & \multirow[t]{2}{*}{0} & \multirow[t]{2}{*}{.12} & \multirow[t]{2}{*}{.27} \\
\hline & Laser (II) & $2.7 \pm 2.9$ & $6.0 \pm 3.5$ & $4.0 \pm 1.7$ & $4.0 \pm 3.7$ & $6.5 \pm 2.9$ & & & \\
\hline \multirow[t]{2}{*}{$\mathrm{CVP}(\mathrm{mm} \mathrm{Hg})$} & Control (I) & $9.9 \pm 2.7$ & $12.1 \pm 3.1$ & $8.5 \pm 2.6$ & $7.5 \pm 2.0$ & $8.3 \pm 2.8$ & \multirow[t]{2}{*}{0} & \multirow[t]{2}{*}{.83} & \multirow[t]{2}{*}{.4} \\
\hline & Laser (II) & $9.7 \pm 2.9$ & $10.4 \pm 2.3$ & $8.5 \pm 3.8$ & $9.0 \pm 3.2$ & $8.6 \pm 2.3$ & & & \\
\hline \multirow{2}{*}{$\begin{array}{l}\text { Cardiac output } \\
\text { (L/min) }\end{array}$} & Control (I) & $2.3 \pm 0.7$ & $2.2 \pm 0.9$ & $1.9 \pm 0.7$ & $1.9 \pm 0.4$ & $1.6 \pm 0.6$ & \multirow[t]{2}{*}{.21} & \multirow[t]{2}{*}{.67} & \multirow[t]{2}{*}{.33} \\
\hline & Laser (II) & $2.2 \pm 0.5$ & $2.0 \pm 0.6$ & $1.9 \pm 0.3$ & $2.1 \pm 0.6$ & $2.1 \pm 0.7$ & & & \\
\hline
\end{tabular}

$\overline{L V E S P}, \mathrm{LV}$ end systolic pressure; $C V P$, central venous pressure. Values are mean $\pm \mathrm{SD}$ of measured hemodynamic parameters. $P$ values were tabulated for time and group effect, and interaction (error) was tabulated by 2-way ANOVA with Bonferroni adjustment for repeated measures.

*Significant $P$ values within groups (baseline vs subsequent values) obtained by paired $t$ statistic are shown in parentheses.

awoke with acute paraplegia; a wound infection and pneumonia developed in the other. After weeks 5 and 6 , all animals became increasingly lethargic, experienced basilar rales, and required markedly reduced doses of thiopental sodium for induction of anesthesia for the 8week study.

None of the laser transmyocardial channels were patent in sheep examined by histologic methods 48 hours and 5 and 8 weeks after infarction. At 48 hours, laser channels were filled with fibrin; surrounding infarcted myocytes remained, and only a few inflammatory cells were present (Fig 1, A). By 5 weeks, granulation tissue with scattered calcifications and a few macrophages and lymphocytes replaced most of the necrotic cardiac myocytes.
Laser channels were not identified, and only very small vessels (equal to 10 to $20 \mu \mathrm{m}$ in diameter) were present (Fig 1, B). At 8 weeks, the infarction was completely replaced with fibrous tissue without evidence of laser channels (Fig 1, C).

All hearts in both groups developed thin-walled anteroapical LV aneurysms (Fig 2). Edges of the infarct were sharply demarcated, and the size and shape of the aneurysms were indistinguishable between groups (Fig 2, $A$ and $B$ ).

Echocardiograms document the evolution from infarction to aneurysm in both groups (Figs 3 and 4). Echocardiograms 1 hour after infarction showed dyskinetic bulging of the infarcted area (Figs 3, $B$, and $4, B$ ) 
Table III. Geometric and functional measurements

\begin{tabular}{|c|c|c|c|c|c|c|c|c|c|}
\hline \multirow[b]{2}{*}{ Measurement } & \multirow[b]{2}{*}{ Group } & \multirow{2}{*}{$\begin{array}{l}\text { Before } \\
\text { infarct }\end{array}$} & \multirow{2}{*}{$\begin{array}{l}\text { After } \\
\text { infarct }\end{array}$} & \multirow{2}{*}{$\begin{array}{c}\text { Two } \\
\text { weeks* }\end{array}$} & \multirow{2}{*}{$\begin{array}{c}\text { Five } \\
\text { weeks* }\end{array}$} & \multirow{2}{*}{$\begin{array}{c}\text { Eight } \\
\text { weeks* }\end{array}$} & \multicolumn{3}{|c|}{ Two-way ANOVA (P value) } \\
\hline & & & & & & & Time & Group & Interaction \\
\hline \multirow[t]{2}{*}{ Number } & Control (I) & 12 & 12 & 10 & 10 & 10 & & & \\
\hline & Laser (II) & 14 & 14 & 10 & 10 & 8 & & & \\
\hline \multirow{2}{*}{$\begin{array}{l}\text { End diastolic } \\
\text { volume }(\mathrm{mL})\end{array}$} & Control (I) & $53.3 \pm 11.1$ & $65.2 \pm 17.2$ & $87.8 \pm 19.4(.00)$ & $89.3 \pm 12.6(.00)$ & $98.3 \pm 16.0(.00)$ & 0 & .02 & .76 \\
\hline & Laser (II) & $49.2 \pm 9.7$ & $54.3 \pm 16.2$ & $72.4 \pm 16.6(.02)$ & $85.4 \pm 21.4(.00)$ & $93.0 \pm 25.3(.00)$ & & & \\
\hline \multirow{2}{*}{$\begin{array}{l}\text { End systolic } \\
\text { volume }(\mathrm{mL})\end{array}$} & Control (I) & $27.9 \pm 6.8$ & $38.5 \pm 9.9$ & $64.5 \pm 19.3(.00)$ & $64.2 \pm 12.4(.00)$ & $75.9 \pm 18.8(.00)$ & 0 & .03 & .48 \\
\hline & Laser (II) & $26.1 \pm 6.9$ & $30.8 \pm 11.5$ & $48.4 \pm 16.8(.01)$ & $64.1 \pm 21.8(.00)$ & $69.6 \pm 22.6(.00)$ & & & \\
\hline \multirow{2}{*}{$\begin{array}{l}\text { Ejection } \\
\text { fraction }(\%)\end{array}$} & Control (I) & $47.4 \pm 8.2$ & $40.4 \pm 7.4$ & $27.6 \pm 8.7(.00)$ & $28.3 \pm 7.3(.00)$ & $23.4 \pm 5.8(.00)$ & 0 & .15 & .51 \\
\hline & Laser (II) & $47.3 \pm 6.7$ & $44.3 \pm 9.2$ & $34.7 \pm 10.1(.01)$ & $27.0 \pm 9.7(.00)$ & $25.9 \pm 6.7(.00)$ & & & \\
\hline \multirow[t]{2}{*}{$\mathrm{SV}(\mathrm{mL})$} & Control (I) & $19.4 \pm 6.4$ & $18.7 \pm 7.2$ & $16.2 \pm 6.2$ & $16.1 \pm 3.4$ & $13.4 \pm 5.2$ & .2 & .66 & .35 \\
\hline & Laser (II) & $18.4 \pm 4.1$ & $16.7 \pm 4.8$ & $15.5 \pm 2.7$ & $17.8 \pm 4.9$ & $17.6 \pm 5.8$ & & & \\
\hline \multirow{2}{*}{$\begin{array}{l}\text { SW } \\
\quad(\mathrm{ergs} \times 10 \mathrm{E} 3)\end{array}$} & Control (I) & $240 \pm 85$ & $206 \pm 80$ & $175 \pm 70$ & $170 \pm 49$ & $138 \pm 51(.01)$ & .02 & .67 & .31 \\
\hline & Laser (II) & $216 \pm 55$ & $176 \pm 67$ & $181 \pm 62$ & $206 \pm 89$ & $178 \pm 78$ & & & \\
\hline \multirow{2}{*}{$\begin{array}{l}\text { SW-LVEDP } \\
\text { slope }\end{array}$} & Control (I) & $38.1 \pm 14.0$ & $25.0 \pm 12.7$ & $27.6 \pm 10.6$ & $31.2 \pm 9.7$ & $27.2 \pm 10.5$ & 0 & .61 & .65 \\
\hline & Laser (II) & $33.0 \pm 15.3$ & $20.0 \pm 7.6(.02)$ & $26.9 \pm 9.1$ & $33.3 \pm 9.9$ & $30.5 \pm 4.3$ & & & \\
\hline
\end{tabular}

Values are mean and SD of measured and calculated geometric and functional parameters. $P$ values were tabulated for time and group effects, and interaction (error) were tabulated by 2-way ANOVA with Bonferroni adjustment for repeated measures.

*Significant $P$ values within groups (baseline vs subsequent values) obtained by paired $t$ statistic are shown in parentheses.

that progressed to LV aneurysm within 8 weeks in all animals (Figs 3, $C$, and 4, C). Immediately after infarction, systolic wall thickness of the infarct decreased in both groups (Table I). Wall thickness of the infarct further decreased by 8 weeks, and there were no significant differences between groups for wall thickness at any time. The LV cavity area during diastole decreased immediately after infarction in the short-axis view that included the infarcted segment in both groups (Table I). The systolic cavity area increased immediately after infarction in both groups. By 8 weeks, diastolic and systolic cavity areas were immensely greater than at baseline. With one exception, there were no significant differences between groups in LV cavity area. At 8 weeks, the long-axis perimeter from aortic valve around the apex to the base of the heart and the length of the akinetic/dyskinetic segment were nearly identical in the 2 groups of sheep (Table I). At no time could the 2 groups of animals be differentiated on the basis of echocardiographic images.

Hemodynamic measurements for the 2 groups of animals at each time point are presented in Table II. By 2way ANOVA there were significant differences over time in all recorded parameters in both groups, except cardiac output. Immediately after infarction, there was a significant reduction in mean arterial pressure in both groups. LVEDP increased in both groups but was not statistically significant in the laser group.

Two-way ANOVA indicated a significant group effect for end-systolic volume (ESV) and end-diastolic volume (EDV; $P=.03$ and $P=.02$, respectively; Table III).
However, there was no significant difference between the 2 groups at any time period for any variable measured with the unpaired $t$ statistic $(P>.05$; Fig 5). By 2way ANOVA there were significant differences over time for EDV and ESV, ejection fraction, SW, and SWLVEDP slope (Table III). As the data indicate, 2 weeks after infarction there was a significant increase in EDV and ESV compared with the baseline, and these parameters continued to increase over the next 6 weeks, indicating ongoing LV cavity enlargement.

Ejection fraction and SW progressively decreased in both groups after infarction (Table III). Ejection fraction was significantly less than baseline by 2 weeks in both groups (Fig 6); SW progressively decreased after infarction (Fig 7, Table III). SV does not significantly change after infarction in either group. The slope of SW-LVEDP decreased significantly in both groups after infarction $(P=.001$ for time), but none of the values at specific time points are significantly less than baseline by paired $t$ test.

\section{Discussion}

This study fails to demonstrate any evidence of revascularization by transmyocardial laser perforations. Within 1 hour of coronary arterial occlusion, echocardiograms of laser-treated and control sheep documented loss of systolic wall thickening, infarct thinning, and dyskinesis of the anterior LV wall at the level of infarction. The magnitude of change was the same in both groups even though all laser perforations were made within 10 to 25 minutes of the onset of 


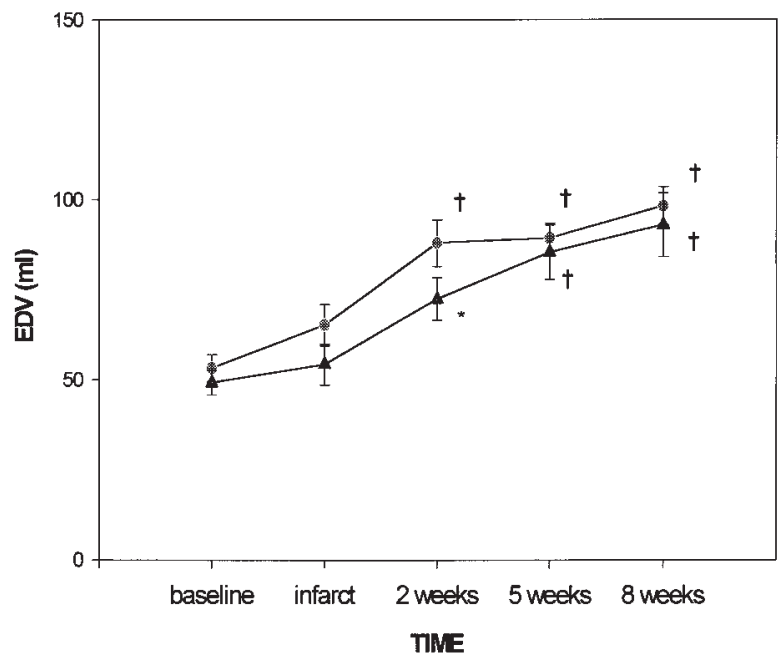

Fig 5. Changes in LVEDV before and after infarction in both groups. Control animals; $\boldsymbol{\Lambda}$, laser-treated sheep. The mean and SEM were plotted for data in Table III. There are no significant differences between groups at any time. ${ }^{*} P<.05$ compared with baseline; $\uparrow P<.01$ compared with baseline.

ischemia. In 1968 Pifarré and colleagues ${ }^{18}$ concluded that myocardial revascularization from the ventricle is not possible on the basis of pressure measurements made in dogs. Our observations support that conclusion.

Our failure to demonstrate patent laser channels is in agreement with previous observations ${ }^{4-7,19}$ and varies with demonstrations of patent channels in patients by imaging techniques ${ }^{20}$ and occasional sightings in patients $^{21}$ and animals. ${ }^{22,23}$ As previously reported in pigs, dogs, and sheep, laser perforations produce a nonspecific inflammatory response $e^{4,5,8}$ that includes increased vascularity by small (5 to $10 \mu \mathrm{m})$ vessels typical of granulation tissue. ${ }^{5,24}$ Specific protein markers of angiogenesis show increased uptake in inflamed tissue surrounding laser perforations but are not directly connected with laser channels. ${ }^{5,24}$ The addition of vascular endothelial growth factor injected at the time of laser therapy does not produce channel patency in pigs. ${ }^{25}$ Thus available data indicate that only a few, and usually no, laser channels remain patent and that the procedure produces a local nonspecific inflammatory reaction that is unable to sustain cardiac myocytes.

Our serial studies also failed to demonstrate any effect of transmyocardial laser perforations on ventricular remodeling after acute anteroapical myocardial infarction. After laser therapy, the LV remodeled into anteroapical aneurysms of the same size and location as observed in untreated animals. Echocardiographic measurements showed no evidence of acute or chronic

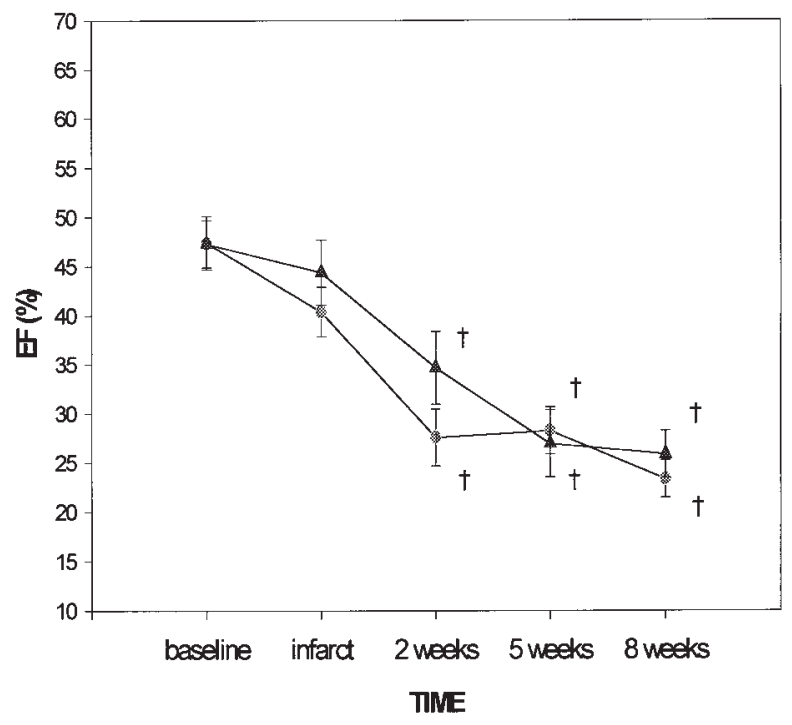

Fig 6. Changes in ejection fraction $(E F)$ before and after infarction in both groups. There were no significant differences between groups at any time. (Symbols are explained in Fig 5.)

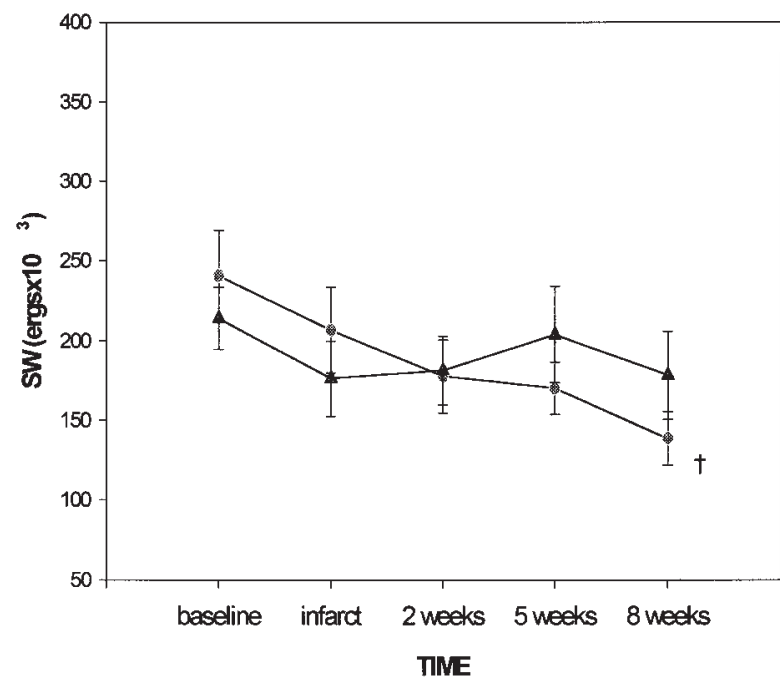

Fig 7. Changes in SW in both groups before and after infarction. There were no significant differences between groups at any time. (Symbols are explained in Fig 5.)

cardiac myocyte preservation after transmyocardial laser perforations of the infarct. In rats, Whittaker and colleagues $^{23,26}$ observed that the presence of patent laser channels or needle channels made 2 months before infarction were associated with reduced necrosis; others also reported smaller infarcts as determined by triphenyl tetrazolium chloride staining in dogs and sheep. ${ }^{22,27}$ The improvement in dogs was small; the sheep study reported an unstated number of irregular, 
patent, fibrin-lined channels observed 30 days after laser therapy of the infarct. These studies and those of Whittaker and colleagues sustain the possibility that patent channels may attenuate the size of an animal infarction; however, as noted earlier, transmyocardial laser perforations rarely remain patent.

The present serial LV functional studies with and without transmyocardial laser perforation are unique because only short-term assessments of function have been made previously in animals. ${ }^{22,28}$ Yano and colleagues $^{28}$ found improvement in preload recruitable SW in dogs treated by partial transmyocardial endocardial laser perforations 1 to 6 hours after 90 minutes of coronary arterial ischemia. Horvath and colleagues ${ }^{22}$ observed very slightly improved epicardial shortening in the area of infarction 30 days after laser perforations. Our serial studies over 8 weeks with multiple measures of ventricular function with the chest intact are convincing evidence that transmyocardial laser perforations of recently infarcted myocardium do not provide meaningful improvement in LV function.

Demonstrations of efficacy of transmyocardial laser perforations of ischemic myocardium, therefore, rest primarily on clinical observations that are subject to alternative explanations. After transmyocardial laser "revasculariztion" of ischemic (hibernating) myocardium $70 \%$ to $100 \%$ of patients experience reduced frequency of angina, ${ }^{2,3}$ decreased use of antianginal medication, ${ }^{2}$ and fewer subsequent hospital admissions ${ }^{2}$; but an improvement in long-term survival has not been documented. Exercise tolerance is increased modestly in patients with anginal relief. ${ }^{3}$ Understandably these results are ascribed to laser revascularization, but studies of Kwong and colleagues ${ }^{29}$ with endocardial and epidardial laser perforations in dogs indicate that afferent nerves from the heart are blocked by the procedure. The mechanism of blockage may be related to epicardial inflammation. ${ }^{29}$ The duration of afferent nerve inhibition is not known, but the observation provides an alternative explanation for consistent relief of angina, reduction of antianginal medications, and modestly improved exercise tolerance in patients treated by transmyocardial laser perforations.

Imaging studies of wall motion and myocardial perfusion before and after transmyocardial laser perforations of ischemic myocardium do not provide convincing evidence of improved myocardial perfusion in areas treated by transmyocardial laser perforation. Horvath and colleagues ${ }^{3}$ reported experience with 13 patients and found no improvement in ejection fraction, wall motion score, thallium perfusion scans, or positron emission tomography (PET), 12 months after operation, but did observe improvement in the ratio of endocardial to epicardial blood flow. In 11 patients, lasered wall segments evaluated for myocardial perfusion at 12 months by PET were approximately evenly divided between "improved, worse, and same." 3 Cooley and colleagues ${ }^{2}$ reported a decrease in perfusion defects after transmyocardial laser perforations in an uncontrolled, multi-institutional study of 200 patients. The average decrease in lateral wall perfusion defects was approximately 1 in 12 wall segments assessed. $^{2}$ These equivocal data underscore limits of imaging technology in patients with diffuse coronary arterial disease and are further confounded by the ability of myocardial leukocytes to take up fluorine-18-2deoxyglucose detected by PET scans. ${ }^{30}$

The limitations of this study are primarily two: an infarct rather than a "hibernating" model was used and the symptom of angina cannot be measured in animals. Clinically, transmyocardial laser revascularization (TMR) has been used in the setting of chronic severe angina refractory to other forms of medical and interventional therapy. Because ours is a model of acute coronary ischemia, the results are not directly applicable to the current clinical applications of TMR therapy. Despite these limitations, the results of this study and careful review of the available literature support the conclusion that transmyocardial laser perforations cause a local nonspecific inflammatory response but do not increase myocardial blood flow sufficiently to prevent myocyte death or to alter ventricular remodeling in the setting of an acute myocardial infarction.

We thank Ms Priscilla Hillyer and Mr Brad Richardson for their considerable help in this study.

\section{REFERENCES}

1. Kohmoto T, Argenziano M, Viet KA, Gu A, DeRosa C, Fisher $\mathrm{PE}$, et al. Assessment of transmyocardial perfusion in alligator hearts. Circulation 1997;94(Suppl):I295.

2. Cooley DA, Frazier OH, Kadipasaoglu KA, Lindenmeir MH, Pehlivanoglu S, Kolff JW, et al. Transmyocardial laser revascularization: clinical experience with twelve-month follow-up. J Thorac Cardiovasc Surg 1996;111:791-9.

3. Horvath KA, Cohn LH, Cooley DA, Crew JR, Frazier OH, Griffith BP, et al. Transmyocardial laser revascularization: results of a multicenter trial with transmyocardial laser revascularization used as sole therapy for end-stage coronary artery disease. J Thorac Cardiovasc Surg 1997;113:645-54.

4. Whittaker P, Kloner RA, Przyklenk K. Laser-mediated transmural myocardial channels do not salvage acutely ischemic myocardium. J Am Coll Cardiol 1993;22:302-9.

5. Fleischer KJ, Goldschmidt-Clermont PJ, Fonger JD, Hutchins GM, Hruban RH, Baumgartner WA. One-month histologic response of transmyocardial laser channels with molecular intervention. Ann Thorac Surg 1996;62:1051-8.

6. Dedic K, Klima T, Cooler DA, Frazier OH, Kadipasaoglu KA, Cihan HB. Transmyocardial laser revascularization: histopathological findings. Cardiovasc Pathol 1998;7:63-7. 
7. Hardy RI, Bove KE, James FW, Kaplan S, Goldman L. A histologic study of laser-induced transmyocardial channels. Lasers Surg Med 1987;6:563-73.

8. Malekan R, Reynolds CA, Kelley ST, Suzuki Y, Bridges CR. Angiogenesis in transmyocardial laser revascularization: a nonspecific response to injury. Circulation 1997;96(Suppl):I564.

9. Vanoverschelde J-LJ, Wijns W, Borgers M, Heyndrickx G, Depré C, Flameng W, et al. Chronic myocardial hibernation in humans. Circulation 1997;95:1961-71.

10. Schaper W. Experimental coronary artery occlusion. III. The determinants of collateral blood flow in acute coronary occlusion. Basic Res Cardiol 1978;73:584-94.

11. White FC, Bloor CM. Coronary collateral circulation in the pig: correlation of collateral flow with coronary bed size. Basic Res Cardiol 1981;76:189-96.

12. Yamamoto N, Kohmoto T, Gu A, Derosa C, Smith CR, Burkhoff D. Transmyocardial revascularization enhances angiogenesis in a canine model of chronic ischemia. Circulation 1997;96(Suppl): I563.

13. Vaslesaeger MM, Van Der Straeten PP, Friart J, Candaele G, Ghys A, Bernard RM. Les anastomoses intercoronariennes telles qu'elles apparaissent a la coronarographie post mortem. Acta Cardiologica 1957;12:365-401.

14. Markovitz LJ, Savage EB, Ratcliffe MB, Bavaria JE, Kreimer G, Iozzo RV, et al. Large animal model of left ventricular aneurysm. Ann Thorac Surg 1989;48:838-45.

15. Kelley ST, Malekan R, Gorman JH III, Jackson BM, Gorman RC, Suzuki Y, et al. Restraining infarct expansion preserves left ventricular geometry and function after acute antero-apical myocardial infarction. Circulation (Submitted)

16. Schiller NB, Shah PM, Crawford M, DeMaria AN, Devereux R, Feigenbaum $\mathrm{H}$, et al. Recommendation for the quantification of the left ventricle by two-dimensional echocardiography: American Society of Echocardiography Committee on Standards, Subcommittee on Quantitation of two-dimensional echocardiograms. J Am Soc Echocardiogr 1989;5:358-62.

17. Nicolosi AC, Weng Z-C, Detwiler PW, Spotnitz HM. Simulated left ventricular aneurysm and aneurysm repair in swine. J Thorac Cardiovasc Surg 1990;100:745-55.

18. Pifarré R, Jasuja ML, Lynch RD, Neville WE. Myocardial revascularization by transmyocardial acupuncture. J Thorac Cardiovasc Surg 1969;58:424-31.

19. Kohmoto T, Fisher P, Gu A, Zhu S-M, Smith CR. Physiology of chronic transmyocardial laser channels created with $\mathrm{CO}_{2}$ laser. Circulation 1995;92(Suppl):I176.

20. Berwing K, Bauer EP, Strasser R, Klovekorn WP, Reuthebuch O, Bertschmann W. Functional evidence of long-term channel patency after transmyocardial laser revascularization. Circulation 1997;96(Suppl):I564.

21. Cooley DA, Frazier OH, Kadipasaoglu KA, Pehlivanoglu S, Shannon RL, Angelini P. Transmyocadial laser revascularization. Anatomic evidence of long-term patency. Texas Heart Inst J 1994;21:220-4.

22. Horvath KA, Smith WJ, Laurence RG, Schoen FJ, Appleyard RF, Cohn LH. Recovery and viability of an acute myocardial infarct after transmyocardial laser revascularization J Am Coll Cardiol 1995;25:258-63.

23. Whittaker P, Kloner RA. Excimer laser channels protect against myocardial ischemia [abstract]. J Am Coll Cardiol 1996;27:13A.

24. Kohmoto T, Fisher PE, DeRosa C, Smith CR, Burkhoff D. Evidence of angiogenesis in regions treated with transmyocardial laser revascularization. Circulation 1996;94(Supp1):I294.
25. Leszek R, Moosdorf R, Bittinger A, Dirk G, Christian BG. Transmyocardial laser revascularization: lack of channel patency in an experimental pig model. Circulation 1996;94(Suppl):I496.

26. Whittaker P, Rakusan K, Kloner RA. Transmural channels can protect ischemic tissue. Circulation 1996;93:143-56.

27. Jeevanandam V, Auteri JS, Oz MC, Watkins J, Rose EA, Smith CR. Myocardial revascularization by laser induced channels. Surg Forum 1990;41:225-7.

28. Yano OJ, Bielefeld MR, Jeevanandam V, Treat MR, Marboe CC, Spotnitz HM, et al. Prevention of acute regional ischemia with endocardial laser channels. Ann Thorac Surg 1993;56:46-53.

29. Kwong KF, Kaneilopoulos GK, Nickols JC, Pogwizd SM, Saffitz JE, Schuessler RB, et al. Transmyocardial laser treatment denervates canine myocardium. J Thorac Cardiovasc Surg 1997; 114:883-90.

30. Wijns W, Melin JA, Leners N, Ferrant A, Keyeux A, Rahier J, et al. Accumulation of polymorphonuclear leukocytes in reperfused ischemic canine myocardium: relation with tissue viability assessed by fluorine-18-2-deoxy-glucose uptake. J Nucl Med 1988;29:1826-32.

\section{Discussion}

Dr Craig R. Smith (New York, NY). This study may prove to be an interesting boundary marker in our understanding of TMR, but for those inclined to see the findings as nails in the coffin of the TMR concept, it is worth reviewing what we already know. In marked contrast to what is reported here, Maricini showed that TMR reduced deaths from 100\% to 27\% in dogs whose LAD was ligated proximal to the first diagonal, which is certainly a substantial salvage under conditions of acute ischemia. The problem with dogs is that they have extensive collaterals, unlike the sheep used in your study. By using sheep, you have chosen a very severe model of acute ischemia and have indeed demonstrated that TMR is not robust enough to salvage myocardium in the absence of collaterals. If we consider what is known clinically, this is not surprising. TMR is known to carry increased risk in patients whose condition is unstable. Nuclear scan evidence of improved perfusion, of the sort you would think would be necessary acutely to prevent aneurysm formation, does not usually show up for at least 3 months. All of this supports the increasingly persuasive notion that TMR functions by stimulating angiogenesis, not by pumping blood through patent channels. I presume you chose a severe model of acute ischemia in which there are no collaterals to test the limits of TMR, but I do not think anyone should be too surprised by the results.

Dr Malekan. I agree with you to a point. We chose this model because, when we started doing this study, there were a lot of reports that the TMR channels do, in fact, stay open. So we hypothesized that if you could induce infarction within a short period of time after producing these channels and if these channels do in fact provide the ischemic myocardium with any blood, then the size of the infarct could be attenuated. Moreover, if there is any other mechanism of TMR, such as angiogenesis, then over the 8-week period we should see a change in the natural history of the infarcted myocardium, such as a decrease in size or a decrease in dyskinesis. This was in fact not true.

Dr Michael Mann (Boston, Mass). It is still not quite clear 
to me what the hypothesis was behind the design of this experiment. As has been mentioned, it is quite clear from previous work that the channels are not patent after laser injury to the heart; however, the functional improvement that has been seen in patients who have undergone this therapy, and the work that has been done histologically, implies that angiogenesis is, in fact, the mechanism of treatment.

Now, we know that angiogenesis requires weeks to months, really, for adequate new collateral blood vessel formation to develop. What was the rationale behind using such an acute injury approach in which the loss of myocardium really occurs within hours to perhaps days? Once that myocardium has suffered that acute injury, it is very unlikely that you are going to regenerate new tissue to improve myocardial function or help prevent aneurysm formation without the implantation of satellite cells, as has been proposed today, or other new technology. So again, if you would, just review what the hypothesis was behind testing TMR, a therapy for chronic ischemia, in such an acute infarction approach. It certainly is not clinically relevant to say that we can bring patients in 9 minutes before their myocardial infarctions for laser treatments. I am not quite clear why you hypothesize this angiogenesis could possibly salvage cells that were dying within hours to days of the initial injury.

Dr Malekan. Let me reiterate that our original hypothesis was, again, if we could provide the ischemic myocardium immediately before infarction, with any additional blood, we might be able to decrease the infarct size. If there is any additional mechanism at TMR, such as angiogenesis, it should change the natural history of the infarct, decreasing the size of the aneurysm or preventing the aneurysm formation totally, but that was not the case here. Your argument incorrectly implies that there is clear scientific evidence that angiogenesis is the mechanism of TMR-induced angina relief. This has not been established. TMR denervates the myocardium, for instance. We presented data at the American Heart Association meeting in October 1997 suggesting that TMR-induced "angiogenesis" may be nothing more than a nonspecific inflammatory response.

Dr Todd Rosengart (New York, NY). Just one quick question to turn these arguments around. Do you have plans of looking at a chronic model? Instead of performing a ligation immediately after TMR, maybe repeat the experiments and ligate 6 weeks later. I think that would address most of the questions that are being asked today.

Dr Malekan. Creating a chronic ischemic model is not easy. In some species there are confounding factors, such as dogs that develop a lot of collaterals. We did try producing a chronic ischemic model in sheep, but sheep have no collateral circulation, and most of the animals died 10 to 14 days after ameroid placement. We are investigating a chronic porcine model of coronary ischemia. 